\title{
VALIDAÇÃO DE UM MODELO DE DIMENSIONAMENTO DE WETLANDS DE MACRÓFITAS AÉREAS PARA SEPARAÇÃO ÁGUA-ÓLEO
}

\author{
L.A. NASCIMENTO ${ }^{1}$; A. E. de MOURA ${ }^{1}$; L.A. SARUBBO $^{2}$; V. A. dos SANTOS ${ }^{2}$. \\ ${ }^{1}$ CGTI - Centro de Gestão de Tecnologia e Inovação \\ ${ }^{2}$ Universidade Católica de Pernambuco - Departamento de Engenharia Química \\ E-mail para contato: lais.an@yahoo.com.br
}

\begin{abstract}
RESUMO - Wetlands construídos povoados por macrófitas aéreas da espécie Eichhornia crassipes (Aguapé) são indicados como uma opção no tratamento de águas residuárias oleosas. Propõe-se neste trabalho o dimensionamento desses wetlands por analogias com condutos livres, reatores semicontínuos e tanques de decantação contínua. O tempo de poda das macrófitas foi modelado com base na cinética de uma reação de primeira ordem. A solução numérica da equação de dimensionamento proposta foi obtida com auxílio da ferramenta Solver (Excel®). Com a construção de quatro (4) protótipos de wetlands em policarbonato, de 3,0 m de comprimento por $0,8 \mathrm{~m}$ de largura por $0,6 \mathrm{~m}$ de altura $(0,4 \mathrm{~m}$ de lâmina d'água), foram realizados testes experimentais de tratamento de águas oleosas. Os resultados mostraram que as mudas resistiram bem às condições impostas e que assimilaram de forma eficiente os íons presentes na água, removendo os poluentes.
\end{abstract}

\section{INTRODUÇÃO}

Como exemplo de método para recuperação de efluentes oleosos, os wetlands construídos, cópias artificiais feitas pelo homem dos wetlands naturais, têm apresentado diversos benefícios por aperfeiçoarem a exploração dos ciclos biogeoquímicos que ocorrem normalmente nos sistemas naturais, de forma que seu regime hidrológico seja controlado. (BUENO, 2013).

Para a construção de protótipos de wetlands construídos foi proposto um modelo de dimensionamento baseado em analogias de funcionamento de condutos livres e decantadores contínuos (BAPTISTA; PINTO, 2003), uma vez que o comportamento do efluente nos wetlands, como proposto neste trabalho, assemelha-se ao apresentado nesses equipamentos.

Após a validação teórica da equação de dimensionamento proposto, foi confeccionado um protótipo de wetland construído onde foi avaliada a sua operação. Entre os aspectos observados, o controle do $\mathrm{pH}$ da água dos wetlands construídos e da densidade das mudas de Eichhornia crassipes (PEDROSO, 2010), representaram grande importância para o bom funcionamento do sistema de separação água-óleo. 
O objetivo deste trabalho foi elaborar um modelo de dimensionamento para wetlands construídos para o tratamento de águas oleosas, permitindo a construção de protótipos e a determinação e modelagem do tempo de poda das macrófitas.

\section{MATERIAL E MÉTODOS}

\subsection{Elaboração do Modelo de Dimensionamento em Planilha Eletrônica} operacionais:

O modelo de dimensionamento foi elaborado com base em três analogias por semelhanças

a) Canal livre - O movimento não depende da pressão interna, mas da inclinação do fundo do wetland e da superfície do líquido.

b) Decantador contínuo - as duas fases entram continuamente por uma extremidade do wetland construído, sendo a fase orgânica retida pelas macrófitas ao longo do tempo de residência, caracterizando uma decantação. A relação entre comprimento e o diâmetro hidráulico permite a existência de condições adequadas de separação entre as fases.

c) Reator semicontínuo - caracterizado pela permanência da fase orgânica em contato com as macrófitas aéreas (regime batelada) e um fluxo contínuo da fase aquosa.

A geometria adotada para o wetland construído foi de um canal de formato retangular, com uma razão entre a largura e a altura da ordem de 2 .

O modelo de dimensionamento encontra-se na Equação 1:

$$
L_{w}=\frac{1}{k \cdot n}\left(\frac{b \cdot h}{b+2 \cdot h}\right)^{2 / 3} \cdot \sqrt{I} \cdot \ln \left(1-\frac{C_{E}-C_{S}}{C_{S}}\right)
$$

Em que:

$\mathrm{n}=$ coeficiente de rugosidade de Manning

$\mathrm{b}=$ largura do canal, $\mathrm{m}$

$\mathrm{h}=$ altura da lâmina de água no canal, $\mathrm{m}$

$\mathrm{I}=$ declividade do canal, $\mathrm{m} / \mathrm{m}$

$\mathrm{k}=$ Constante de velocidade de consumo do poluente, $\mathrm{s}^{-1}$

$\mathrm{C}_{\mathrm{E}}=$ concentração do poluente na entrada do wetland, $\mathrm{ppm}$

$\mathrm{C}_{\mathrm{S}}=$ concentração do poluente na descarga do wetland, ppm

Através da ferramenta Solver do software Microsoft Office Excel foram testados valores de comprimento total de um wetland construído ( $\mathrm{Lw}$ ) que proporcionassem uma concentração 
aceitável de poluente na descarga (Cs). Os dados utilizados para o desenvolvimento da Equação (1) se encontram na Tabela 1.

Tabela 1 - Parâmetros utilizados na equação de dimensionamento.

\begin{tabular}{ccc}
\hline Parâmetro & Valor & Unidade \\
\hline Comprimento do wetland construido (Lw) & $12^{\mathrm{a}}$ & $\mathrm{m}$ \\
Altura da lâmina d'água (h) & 0,4 & $\mathrm{~m}$ \\
Largura do wetland construído (b) & 0,8 & $\mathrm{~m}$ \\
Coeficiente de rugosidade de Manning (n) & $0,009^{\mathrm{b}}$ & - \\
Declividade do wetland construído (I) & 0,005 & $\mathrm{~m} / \mathrm{m}$ \\
Concentração de óleo na alimentação (CE) & $20^{\mathrm{c}}$ & $\mathrm{ppm}$ \\
Concentração de óleo na saída (CS) & $10^{\mathrm{c}}$ & $\mathrm{ppm}$ \\
Vazão do wetland construído (Q) & 0,000833 & $\mathrm{~m}^{3} / \mathrm{s}$ \\
\hline
\end{tabular}

Fonte: Galvão, 2009

${ }^{\text {a }} \mathrm{O}$ valor utilizado de 12 metros corresponde a soma dos comprimentos dos 4 tanques de 3 metros cada que compõem o sistema de wetlands construídos.

${ }^{\mathrm{b}} \mathrm{O}$ valor escolhido foi o do coeficiente para tubos de vidro, devido a semelhança com o material utilizado na construção.

${ }^{c}$ Os valores de concentração do óleo mineral tiveram como base o valor limite de $20 \mathrm{mg} / \mathrm{L}$ ( 20 ppm), definido na Resolução CONAMA n 430/2011 que dispõe sobre as condições e padrões de lançamento de efluentes.

\subsection{Construção dos Protótipos}

$\mathrm{O}$ arranjo experimental foi composto por quatro wetlands construídos com geometrias de canais retangulares (Figura 1). Os protótipos feitos de policarbonato possuem as seguintes medidas: paredes com 0,01 $\mathrm{m}$ de espessura, $3 \mathrm{~m}$ de comprimento, $0,8 \mathrm{~m}$ de largura e $0,6 \mathrm{~m}$ de altura. Os protótipos foram conectados através de mangueiras de silicone, por onde ocorreu a circulação da mistura água-óleo impulsionada por uma bomba hidráulica. O nível da lâmina d'água foi mantido em $0,4 \mathrm{~m}$ com auxílio de uma torneira bóia para caixa d'água. A distribuição da água oleosa foi projetada para ser efetuada através de uma tubulação perfurada disposta transversalmente na entrada do primeiro protótipo, de modo que o efluente percorresse a totalidade do leito no sentido longitudinal, ao longo do qual se processou o tratamento, melhorando a eficiência da separação água-óleo. 


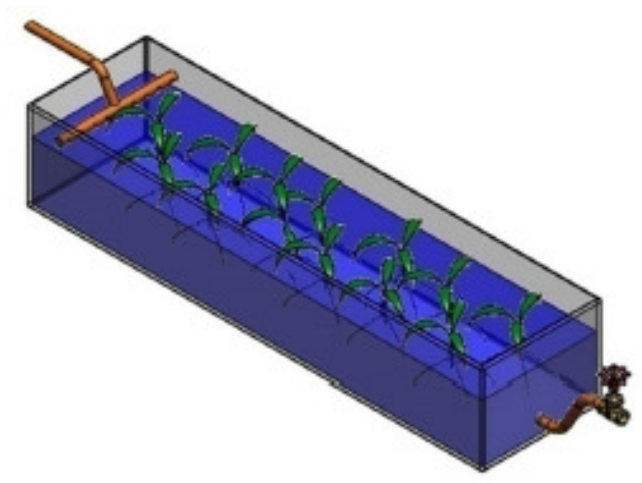

Figura 1 - Esquema com componentes básicos do protótipo de wetland construído.

\subsection{Determinação do Tempo de Poda}

Inicialmente foram colocadas 35 mudas de Eichhornia crassipes em cada protótipo com $2,4 \mathrm{~m}^{2}$, preenchendo $50 \%$ de suas áreas $\left(1,2 \mathrm{~m}^{2}\right)$. O espaço livre (50\% da área) foi utilizado para o estudo do tempo necessário de poda.

A quantidade de mudas de Eichhornia crassipes dobra a cada 14 dias, aproximadamente (KAWAI; GRIECO, 1983). Portanto, um wetland construído com 50\% de espaço livre terá sua área totalmente preenchida neste intervalo. Logo, o tempo necessário para reduzir a metade o espaço inicialmente livre será de 7 dias (Figura 2).

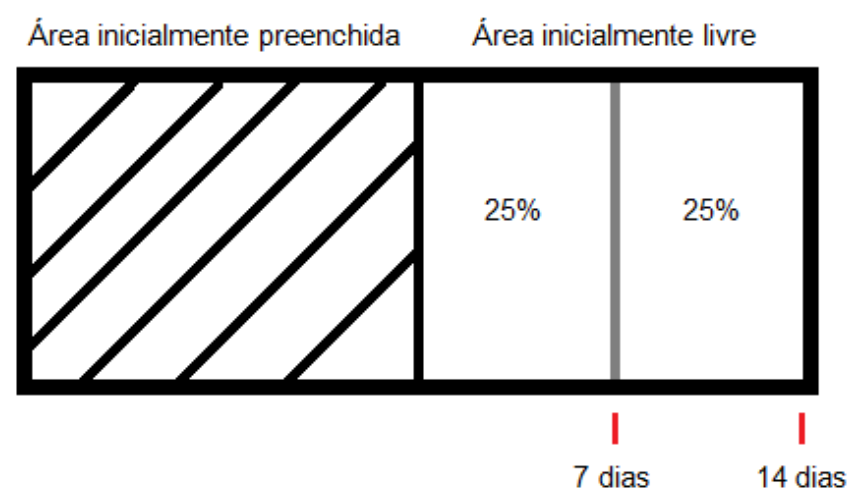

Figura 2 - Preenchimento da área livre superficial do wetland construído pelas macrófitas

Observa-se na Figura 2 que após 7 dias o wetland construído ficará $75 \%$ preenchido pelas mudas de Eichhornia crassipes. De acordo com um estudo realizado por Kawai e Grieco (1987), o wetland construído será mais eficiente quando estiver aproximadamente $70 \%$ ocupado pelas macrófitas. 
O tempo de poda foi determinado através da Equação 2, baseada na cinética de primeira ordem:

$$
\ln A=\ln A o-k_{\text {redução }} . t
$$

Em que:

$\mathrm{A}_{\mathrm{o}}$ - área inicial livre (sem macrófitas), $\mathrm{m}^{2}$

A - área livre após um determinado tempo, $\mathrm{m}^{2}$

$\mathrm{t}$ - tempo, dias

$\mathrm{k}_{\text {redução }}$ - constante de redução da área livre, $\mathrm{d}^{-1}$.

\section{RESULTADOS E DISCUSSÃO}

A partir da resolução da Equação (1) na ferramenta Solver da planilha eletrônica Excel, foi encontrado o valor de $0,155 \mathrm{~s}^{-1}$ para a constante de velocidade de consumo do poluente $(\mathrm{k})$. Fixando este valor, foram variadas as concentrações de óleo na alimentação (CE) entre a faixa de 40 a 20 ppm afim de determinar qual comprimento é necessário para reduzir estas concentrações de óleo para $10 \mathrm{ppm}$ na saída (CS) dos wetlands construídos (Figura 3). Observa-se que para obter uma concentração satisfatória na saída é necessário que o comprimento do wetland construído seja capaz de proporcionar um tempo suficiente para retenção do poluente.

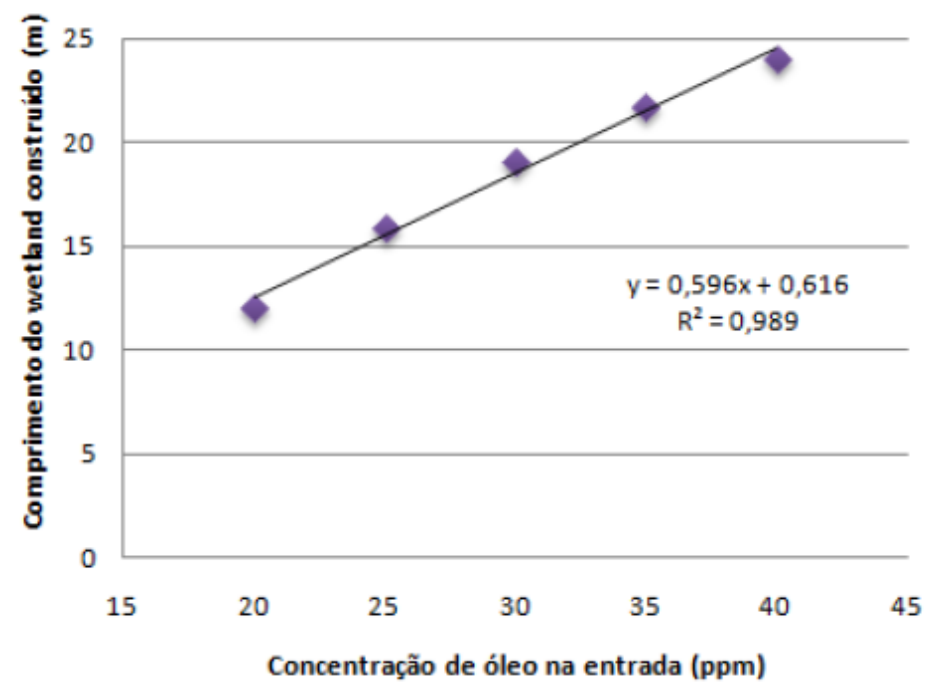

Figura 3 - Comportamento do comprimento do wetland construído em relação a variação de concentrações de óleo na entrada 
A constante de redução da área livre $\left(k_{\text {redução }}\right)$ foi determinada através da Equação 2. Para o intervalo de tempo estudado (tempo necessário para reduzir a área livre pela metade), obteve-se $\mathrm{k}_{\text {redução }}$ igual a $0,099 \mathrm{~d}^{-1}$. Isto significa que a cada um dia, aproximadamente $0,099 \mathrm{~m}^{2}$ da área do wetland é ocupada pelas macrófitas.

\section{CONCLUSÕES}

A ferramenta Solver da planilha eletrônica Excel permitiu uma validação dos parâmetros escolhidos para o modelo de dimensionamento do wetland construído proposto. Através dos resultados obtidos da equação de dimensionamento foi possível concluir que a operação do wetland construído se assemelha a de um decantador horizontal contínuo líquido-líquido devido ao fato da captação da água tratada se dar pela base com um acúmulo de óleo na lâmina d'água, separando as fases.

A partir da determinação da constante de redução de área livre concluiu-se que é necessário realizar a poda das macrófitas a cada 7 dias, visando manter a área $70 \%$ coberta pelas mudas. Além de controlar a densidade das macrófitas, a poda mantém o $\mathrm{pH}$ ótimo para o cultivo das mesmas, uma vez que o pH é influenciado pela disponibilidade de matéria orgânica na água do meio, devido a liberação de $\mathrm{CO}_{2}$ decomposição das plantas e posterior formação de ácido carbônico, acidificando a água.

\section{AGRADECIMENTOS}

Os autores são gratos ao Centro de Gestão de Tecnologia e Inovação e ao Programa de Recursos Humanos da Agência Nacional de Petróleo para o Setor Petróleo e Gás (PRH-28) pelos suportes financeiros e bolsas.

\section{REFERÊNCIAS}

BAPTISTA, M.B.; PINTO, M.M.L. Pinto. Fundamentos de Engenharia Hidráulica. 2a. rev. Belo Horizonte: UFMG/Escola de Engenharia, 2003. 437 p.

BUENO, Rodrigo de Freitas. Aplicação de Wetlands Construídos como Sistemas Descentralizados no Tratamento de Esgoto. Disponível em: < http://www.abessp.org.br/arquivos/evento210613/02.pdf>. Acesso em: 06 mar. 2014.

FOGLER, H Scott. Elementos de Engenharia das Reações Químicas. 4. Ed. Rio de Janeiro: LTC, 2012.

GALVÃO, Ana Fonseca. Comportamento Hidráulico e Ambiental de Zonas Húmidas Construídas Para o Tratamento de Águas Residuais. 2009. 310 p. - Dissertação para obtenção do Grau de Doutor em Engenharia do Ambiente. Universidade Técnica de Lisboa, Lisboa, 2009. 
KAWAI, H.; GRIECO, V. M. Utilização do aguapé para tratamentos de esgosto doméstico. Estabelecimento de critérios de dimensionamento de lagoa de aguapé e abordagem de alguns problemas operacionais. Revista DAE, São Paulo. n. 135, p. 79-90, 1983.

PEDROSO, Geovani Aguiar. Utilização do aguapé e da cal no tratamento da água residuária do café processado por via úmida. 2010. 50 p. Trabalho de Conclusão de Curso para obtenção de grau de tecnólogo em Cafeicultura. Instituto Federal de Educação, Ciência e Tecnologia Sul de Minas Gerais, Muzambinho, 2010. 